\title{
Slight pH Fluctuations in the Gold Nanoparticle Synthesis Process Influence the Performance of the Citrate Reduction Method
}

\author{
Braulio Contreras-Trigo ${ }^{1}$, Víctor Díaz-García ${ }^{1}{ }^{(10}$, Enrique Guzmán-Gutierrez ${ }^{2}$ (D), \\ Ignacio Sanhueza $^{3}$ (D), Pablo Coelho ${ }^{3}$ (D), Sebastián E. Godoy ${ }^{3}$ (D), Sergio Torres ${ }^{3}$ (D) \\ and Patricio Oyarzún 1,* (iD) \\ 1 Facultad de Ingeniería y Tecnología, Universidad San Sebastián, Lientur 1457, Concepción 4080871, Chile; \\ bcontrerast@docente.uss.cl (B.C.-T.); victor.diazg@uss.cl (V.D.-G.) \\ 2 Facultad de Ciencias de la Salud, Universidad San Sebastián, Lientur 1457, Concepción 4080871, Chile; \\ enrique.guzman@uss.cl \\ 3 Departamento de Ingeniería Eléctrica, Facultad de Ingeniería, Universidad de Concepción, \\ Concepción 4030000, Chile; ignacio.sanhueza.ruiz@gmail.com (I.S.); pcoelho@udec.cl (P.C.); \\ segodoy@udec.cl (S.E.G.); sertorre@udec.cl (S.T.) \\ * Correspondence: patricio.oyarzun@uss.cl; Tel.: +56-41-2487-962
}

Received: 4 June 2018; Accepted: 5 July 2018; Published: 12 July 2018

\begin{abstract}
Gold nanoparticles (AuNPs) are currently under intense investigation for biomedical and biotechnology applications, thanks to their ease in preparation, stability, biocompatibility, multiple surface functionalities, and size-dependent optical properties. The most commonly used method for AuNP synthesis in aqueous solution is the reduction of tetrachloroauric acid $\left(\mathrm{HAuCl}_{4}\right)$ with trisodium citrate. We have observed variations in the $\mathrm{pH}$ and in the concentration of the gold colloidal suspension synthesized under standard conditions, verifying a reduction in the reaction yield by around $46 \%$ from $\mathrm{pH} 5.3(2.4 \mathrm{nM})$ to $\mathrm{pH} 4.7(1.29 \mathrm{nM})$. Citrate-capped AuNPs were characterized by UV-visible spectroscopy, TEM, EDS, and zeta-potential measurements, revealing a linear correlation between $\mathrm{pH}$ and the concentration of the generated AuNPs. This result can be attributed to the adverse effect of protons both on citrate oxidation and on citrate adsorption onto the gold surface, which is required to form the stabilization layer. Overall, this study provides insight into the effect of the $\mathrm{pH}$ over the synthesis performance of the method, which would be of particular interest from the point of view of large-scale manufacturing processes.
\end{abstract}

Keywords: gold nanoparticles; citrate reduction method; $\mathrm{pH}$-effect; concentration

\section{Introduction}

Gold nanoparticles (AuNPs) have emerged as a promising platform for a growing number of biomedical and biotechnology applications in the fields of sensing [1], molecular diagnostic [2], therapeutic [3], and imaging [4], owing to their stability, biocompatibility, remarkable physicochemical properties, and easy surface functionalization with a wide range of ligands [5,6]. A prominent optic feature of AuNPs arises from the collective oscillation of the conduction electrons in the presence of an incident light, the so-called surface plasmon resonance (SPR) [7]. This phenomenon causes a sharp and intense absorption band in the visible range, which can be readily tuned by varying the particle size, shape, and the surrounding physicochemical environment [8]. Thus, label-free colorimetric sensors based on AuNPs (nanobiosensors) have been widely proposed as a promising analytical for selective binding and detection of chemical and biological targets, including metal ions [9], antibiotics [10], mycotoxins [11], as well as a large number of microorganisms [12]. 
As concerns the preparation of the colloidal gold nanoparticles, various chemical routes, including the use of chemical reductants [13] and several photochemical methods based on UV irradiation [14], $\gamma$-irradiation [15], and laser irradiation [16], have been widely studied for different purposes of application. However, the classical "citrate reduction method" proposed by Turkevich in 1951 [17], and latter modified by Frens in 1973 [18], remains the most widely employed synthesis procedure, since AuNPs can be produced in a straightforward manner to obtain highly stable monodisperse particles with uniform spherical shape and narrow-size distributions ranging between $10-20 \mathrm{~nm}$ in diameter. This method is based on the aqueous-phase reduction of an $\mathrm{Au}^{3+}$ precursor $\left(\mathrm{HAuCl}_{4}\right.$; gold salt) with sodium citrate near the boiling point of the reaction mixture, which produces a stable solution of metallic gold nanoparticles (colloidal gold) [19]. Recently, the use of citrate containing redox active ionic liquids has proved effective for simple synthesis of stable metal nanoparticles [20].

Citrate ions play a key role, since they act both as a reductant, converting gold ions $\left(\mathrm{Au}^{3+}\right)$ into gold atoms $\left(\mathrm{Au}^{0}\right)$, and as a protective agent that stabilizes the formed nanoparticles, preventing particle growth and aggregation via electrostatic repulsion (citrate capped AuNPs) [21]. Thus, at high citrate concentrations, smaller particles are covered and stabilized by this ion, while at low concentrations particle growth continues due to incomplete coverage, leading to the formation of AuNPs with larger particle size. A third role of citrate is as a mediator of the reaction mixture $\mathrm{pH}$, through which it has a dramatic effect on the size, polydispersity, and morphology of the resulting AuNPs [22,23]. pH control on the citrate reduction method has been widely explored regarding its relationship with the size distribution of the AuNPs [24]. However, up until now the correlation of this parameter with the concentration of the resulting nanoparticles had not been described, which is of particular interest for citrate mediated synthesis of colloidal AuNPs to meet large scale manufacturing criteria [25].

The acid-base behavior of the AuNPs is provided by the citrate layer, which imparts a negative charge onto the colloidal particle surface. Citrate is a tricarboxylic acid (polyanion) with three pKa values $(\mathrm{pKa} 1=3.06, \mathrm{pKa} 2=4.74$, and $\mathrm{pKa} 3=5.4)[26]$, which participate in the following chemical equilibria (Figure 1):

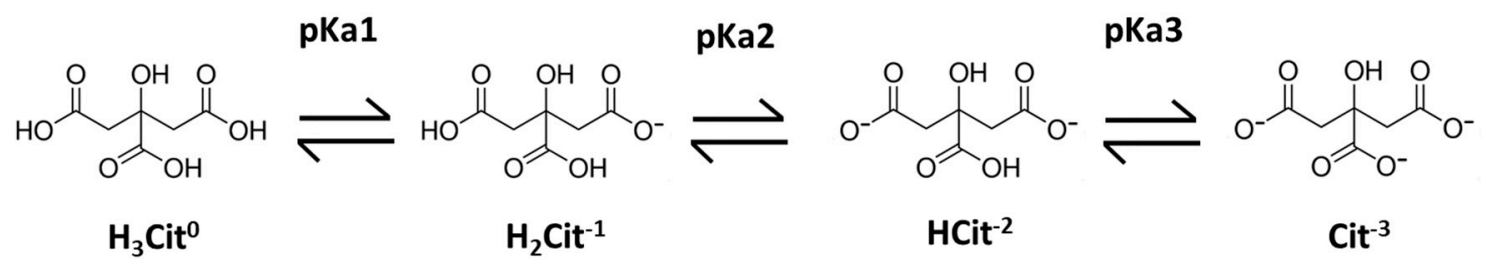

Figure 1. Chemical equilibria of citrate in aqueous solution.

In this study, we investigated the relationship between typically occurring $\mathrm{pH}$ fluctuations of the colloidal suspension (between 4.5 and 5.3) and the concentration of the gold nanoparticles, providing valuable information regarding the synthesis performance of the method. AuNPs were characterized in terms of their concentration (optical density determinations), morphology, and surface charge, by carrying out transmission electron microscopy (TEM) examination, scanning electron microscopy with energy dispersive $\mathrm{X}$-ray spectroscopy (EDS), and zeta potential analysis.

\section{Materials and Methods}

\subsection{Preparation of Gold Nanoparticles (AuNPs)}

Synthesis of AuNPs was carried out according to the procedures described in the citrate reduction method $[17,18]$. Briefly, $0.0394 \mathrm{~g}$ of tetrachloroauric acid $\left(\mathrm{HAuCl}_{4} \cdot 3 \mathrm{H}_{2} \mathrm{O}\right)$ (Sigma Aldrich Chemical Company, Atlanta, GA, USA) was dissolved in $100 \mathrm{~mL}$ of nanopure water (18 $\mathrm{M} \Omega$ of resistance) in a three-neck round flask $\left(1 \mathrm{mM} \mathrm{HAuCl}_{4}\right)$ connected to reflux condenser. The resulting solution was isovolumetrically heated to boiling point under stirring and refluxed. Then, $10 \mathrm{~mL}$ of a $38.8 \mathrm{mM}$ 
trisodium citrate solution was preheated to $60^{\circ} \mathrm{C}$ and quickly added to the boiling solution of $\mathrm{HAuCl}_{4}$ under vigorous stirring. After the solution turned from pale yellow to black and to deep red, it was refluxed for additional $30 \mathrm{~min}$ and subsequently cooled to room temperature without stirring for at least $2 \mathrm{~h}$. The formed nanoparticle suspension was filtered through Millipore Nylon filter $(0.45 \mu \mathrm{m})$ and preserved in the dark at $4{ }^{\circ} \mathrm{C}$ for subsequent $\mathrm{pH}$ determination and characterization of the AuNPs.

\subsection{AuNP Concentration}

The concentration of gold synthesized under different $\mathrm{pH}$ conditions was determined by UV-Vis spectroscopy using an Epoch ${ }^{\mathrm{TM}}$ Microplate Spectrophotometer (Bio-Tek Instruments, Winooski, VT, USA). $100 \mu \mathrm{L}$ of each sample were transferred in duplicate into the microplate wells and the absorption spectra was recorded in the visible region $(400$ to $700 \mathrm{~nm}$ ). The absorption maximum at the SPR band $(520 \mathrm{~nm})$ was employed to calculate the AuNP concentration according to the Beer-Lambert law, by using an extinction coefficient $(\varepsilon)$ of $2.01 \times 10^{8} \mathrm{M}^{-1} \mathrm{~cm}^{-1}$ [27].

\subsection{Electron Microscopy Analysis}

The morphology and size of the AuNPs was determined by transmission electron microscopy with 4 Å resolution (TEM; JEOL-JEM 1200EX-II, Tokyo, Japan), using a Gatan CCD camera for image acquisition (model 782; Gatan, Inc., Pleasanton, CA, USA). The AuNPs samples were drop-cast on formvar/carbon-coated 200 mesh copper grids, which were subsequently retracted and allowed to dry in air at room temperature. Particle sizes and frequency histograms were obtained by measuring the diameter of 100 nanoparticles using the Image software [28], while the percentage of spherical particles was determined through visual inspection of 100 nanoparticles. In addition, elemental analysis of the gold colloidal suspensions was carried out by energy-dispersive X-ray analysis (EDS system; Oxford Instruments, Oxford, UK) using scanning electron microscopy with a resolution of $133 \mathrm{eV}$ (SEM; JEOL JSM 6380LV, Tokyo, Japan).

\subsection{Surface Charge Characterization ( $p Z$ )}

Zeta-potential measurements of AuNPs were measured on a zeta-potentiometer (Nano-ZS90, Malvern Instruments, Westboroug, MA, USA) at room temperature and scattering angle of $90^{\circ}$ and $1 \mathrm{~cm}$ pathlength. A diluted suspension of AuNPs ( $100 \mu \mathrm{L}$ diluted to $1 \mathrm{~mL}$ nanopure water) were employed for the analyses. The Malvern Zetasizer Software version 7.12 was employed to analyze the collected data.

\section{Results and Discussion}

Citrate-capped AuNPs were synthesized by the citrate reduction method and immediately characterized in terms of the $\mathrm{pH}$ of the solutions, as well as by UV-visible spectroscopy, size, morphology, elemental composition, and surface charge properties.

\section{1. pH Effect on the Concentration}

Figure 2 presents the absorption spectra of the AuNPs solutions synthesized at variable $\mathrm{pH}$ values $(4.7,5.0$, and 5.3), showing the typical curve with a characteristic maximum at $520 \mathrm{~nm}$ associated to the SPR band. However, differences in the absorbance values at this peak revealed that $\mathrm{pH}$ of the synthesis medium had a relevant effect on the resulting concentration of the nanoparticles. The AuNPs concentration varied in a directly proportional manner as a function of the $\mathrm{pH}$ (positive correlation), reaching $\mathrm{pH} 5.3$ and about 1.8-fold the concentration $(2.4 \mathrm{nM})$ than the one obtained at $\mathrm{pH} 4.7(1.29 \mathrm{nM})$ (see Table 1). This correlation is highly linear within the monitored $\mathrm{pH}$ range (4.7-5.3), with a correlation coefficient $\left(\mathrm{r}^{2}\right)$ of 0.9987 . 


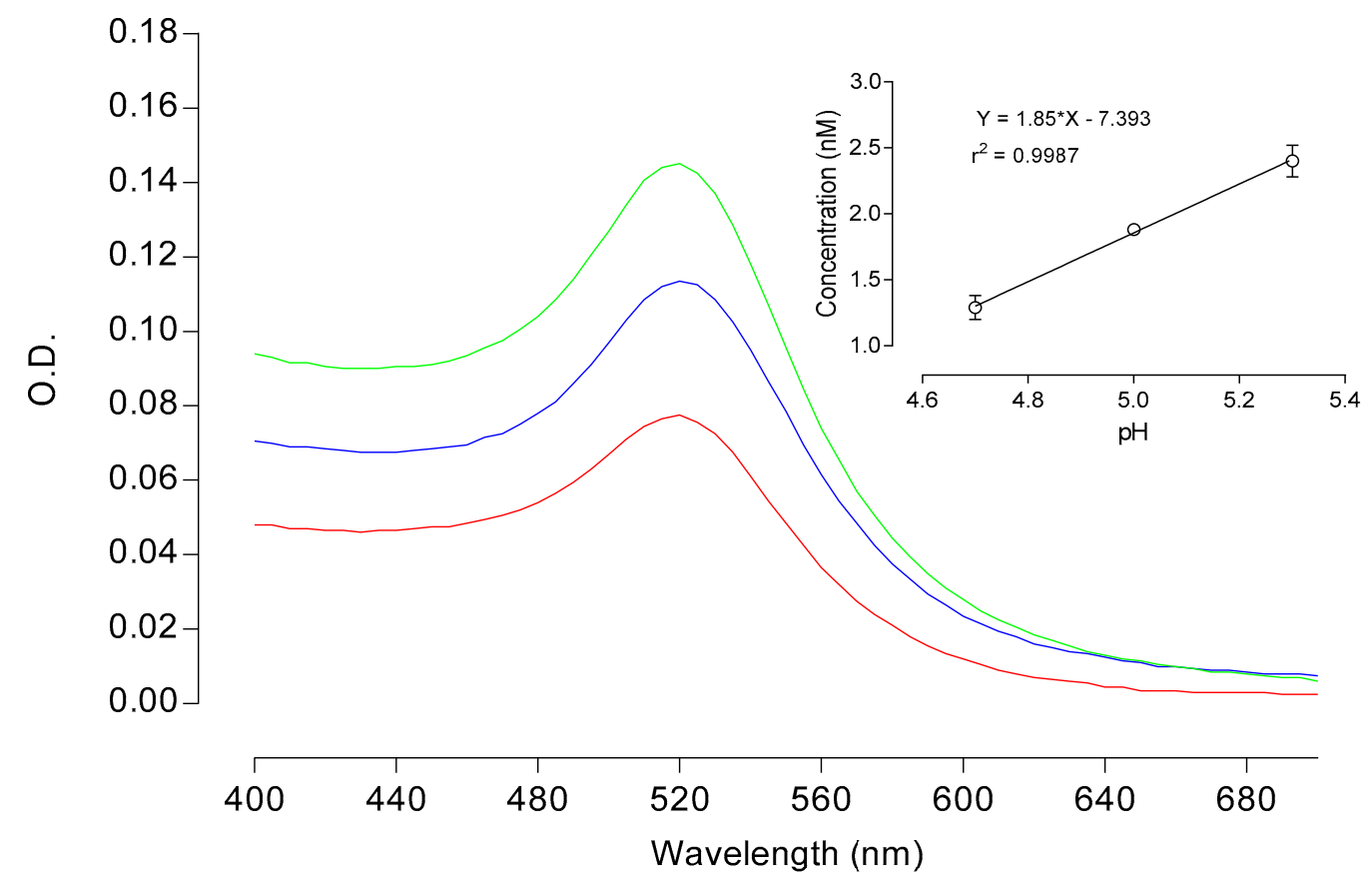

Figure 2. Absorption spectra of gold nanoparticles (AuNPs) obtained by the citrate reduction method at $\mathrm{pH} 4.7$ (red line), 5.0 (blue line), and 5.3 (green line). The inset shows the linear correlation curve between $\mathrm{pH}$ and AuNP concentration is presented. Optical densities (O.Ds) correspond to the mean values calculated from independent determinations $(n=2)$.

Table 1. Zeta potential, concentration and diameter of AuNPs at $\mathrm{pH} 4.7,5.0$, and 5.3.

\begin{tabular}{ccccccc}
\hline $\mathbf{p H}$ & $\begin{array}{c}\text { Zeta Potential } \\
\mathbf{M e a n}(\mathbf{m V})\end{array}$ & $\begin{array}{c}\text { Peak 1 } \\
\mathbf{( m V )}\end{array}$ & $\begin{array}{c}\text { Peak 2 } \\
\mathbf{( m V )}\end{array}$ & $\begin{array}{c}\text { Peak 3 } \\
\mathbf{( m V )}\end{array}$ & $\begin{array}{c}\text { Concentration } \\
(\mathbf{n M})\end{array}$ & $\begin{array}{c}\text { Diameter } \\
(\mathbf{n m})\end{array}$ \\
\hline 4.7 & $-42.2 \pm 35.1$ & $-58.5 \pm 15.2$ & $-26.7 \pm 8.2$ & $16.8 \pm 7.1$ & $1.29 \pm 0.09$ & $13.92 \pm 1.45$ \\
5.0 & $-44.9 \pm 5.1$ & $-44.9 \pm 5.1$ & & & $1.88 \pm 0.03$ & $14.94 \pm 1.53$ \\
5.3 & $-45.7 \pm 7.6$ & $-45.7 \pm 7.6$ & & & $2.40 \pm 0.12$ & $15.50 \pm 1.51$ \\
\hline
\end{tabular}

\subsection{AuNPs Characterization}

TEM analysis of the AuNPs samples proved the nanoparticles have comparable diameters between 13.9-15.5 $\mathrm{nm}$ for the tree monitored $\mathrm{pH}$ values, with a similar morphology distribution (Figure 3; Table 1). The percentage of spherical nanoparticles was slightly higher at pH 5.3 (77\%) when compared to the percentage obtained with pH 5.0 (57\%) and $\mathrm{pH} 4.7$ (62\%), which would favor shape homogeneity of the nanoparticles. By contrast, commercial AuNPs showed the least sphericity (51\%). These observations are consistent with the optical behavior exhibited by the nanoparticle suspensions, which share identical wavelength associated to the SPR peak (UV-Vis spectrograms, Figure 2).

In addition, energy dispersive $X$-ray spectrometry (EDS) elemental analysis confirmed the presence of $\mathrm{Au}, \mathrm{C}, \mathrm{O}$, and $\mathrm{Na}$ forming part of the citrate layer adsorbed on the AuNPs (Figure 4). Sodium ions play an important role in stabilizing high capping of the gold surface by carboxylate anions [29]. 


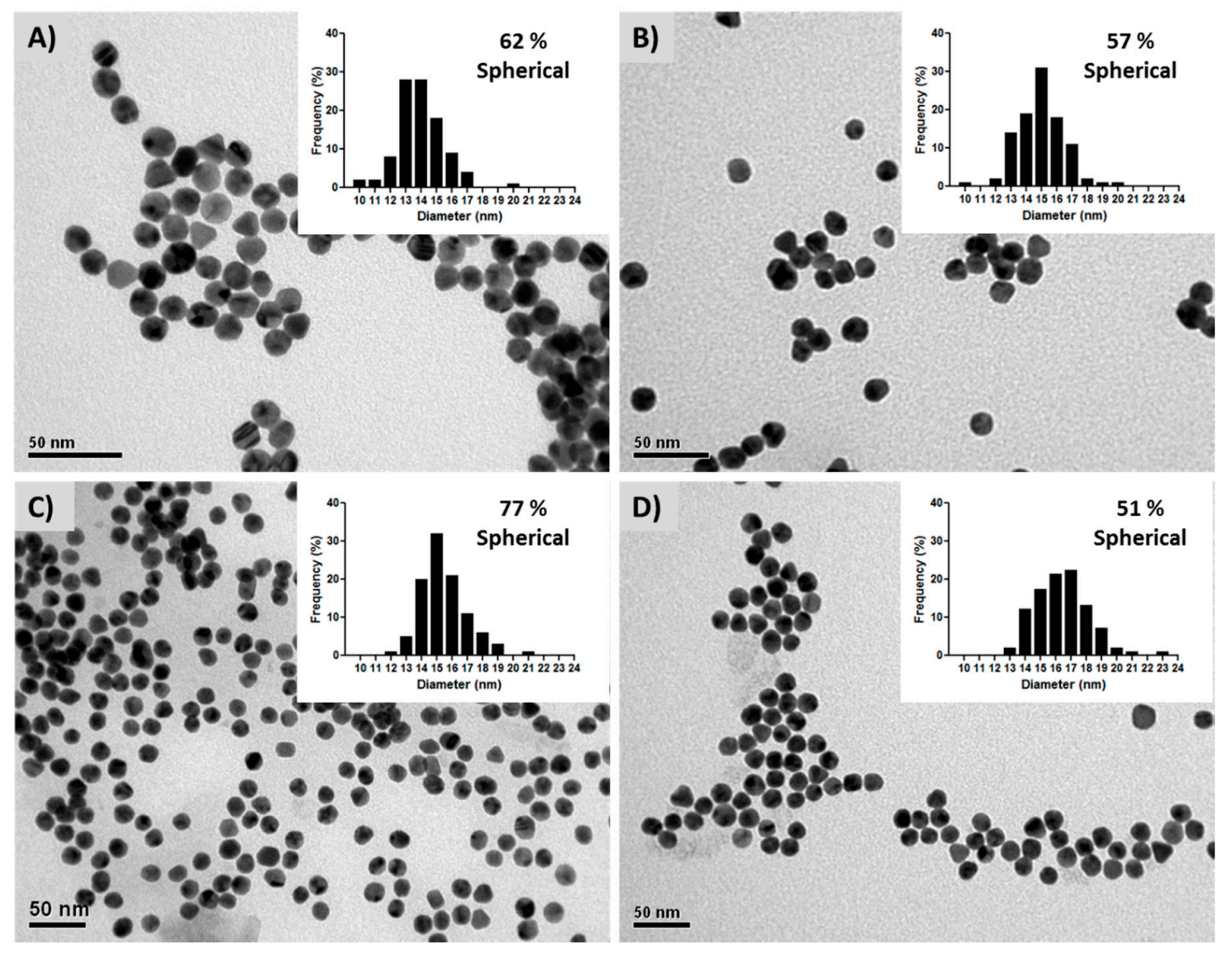

Figure 3. Transmission electron microphotographs of AuNPs at $\mathrm{pH} 4.7$ (A), 5.0 (B), and 5.3 (C), and commercial AuNPs ( $\mathrm{pH}$ 5.0) with an average diameter of $16.42 \pm 1.76 \mathrm{~nm}$ (D). Histograms with the respective particle size distributions and the percentage of spherical nanoparticles are included as insets within each microphotography.

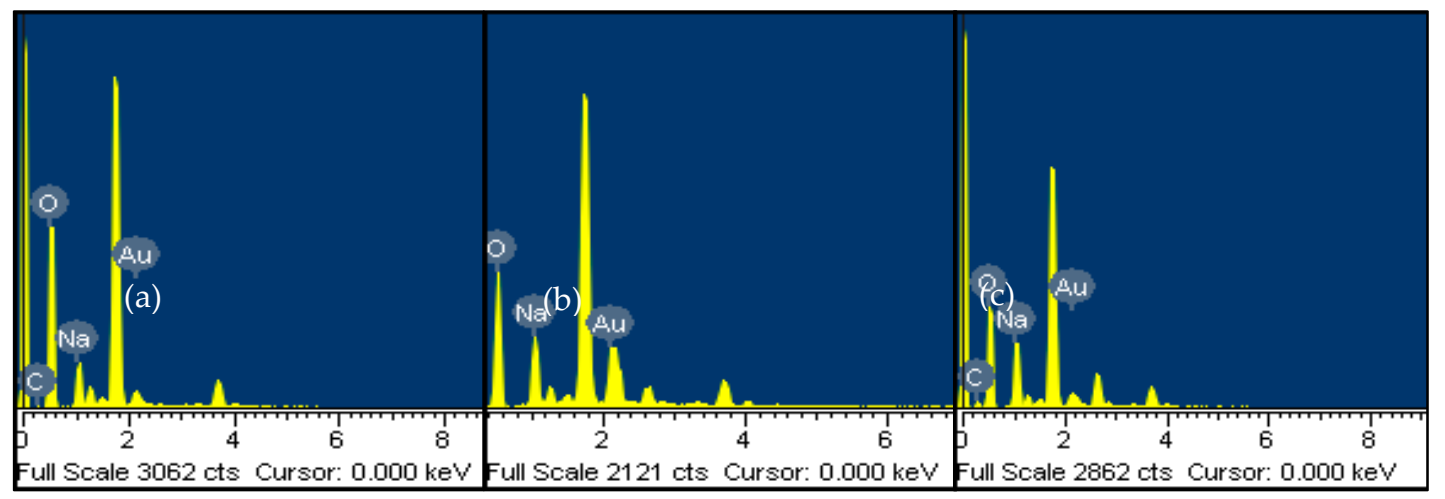

Figure 4. Energy dispersive X-ray spectrometry (EDS) spectra of gold colloidal suspensions at $\mathrm{pH} 4.7$ (a), 5.0 (b), and 5.3 (c). Highest peaks (not labeled on the spectra) correspond to the silicon from the glass supports.

\subsection{Surface Charge Analysis}

Under standard experimental conditions employed in the present study the binding of citrate ions onto the surface of AuNPs occurs electrostatically through negative oxygen atoms of carboxylic groups (oxyanions) at the ends of the citrate molecule [29]. Thus, at pH 4.7 (close to pKa2) similar amounts of $\mathrm{H}_{2} \mathrm{Cit}^{-1}$ and $\mathrm{HCit}^{-2}$ implies a lesser availability of deprotonated carboxylic groups, while at $\mathrm{pH} 5.3$ 
(close to pKa3) the dominant species $\mathrm{HCit}^{-2}$ and $\mathrm{Cit}^{-3}$ would determine a greater capability of citrate anions to coordinate to the metal surface.

The negative charge of citrate-stabilized AuNPs was confirmed through zeta potential analysis (pZ), revealing the influence of $\mathrm{pH}$ on the surface charge from the distribution of the $\mathrm{pZ}$ values (Figure 5). Thus, as the monitored $\mathrm{pH}$ fluctuated from 4.7 to 5.3, the shape of the curves reveals a progressive narrowing on the dispersion of the $\mathrm{pZ}$ values of the AuNPs, which accounts for a greater stabilization of the nanoparticles as a consequence of the presence of mostly deprotonated citrate anions.

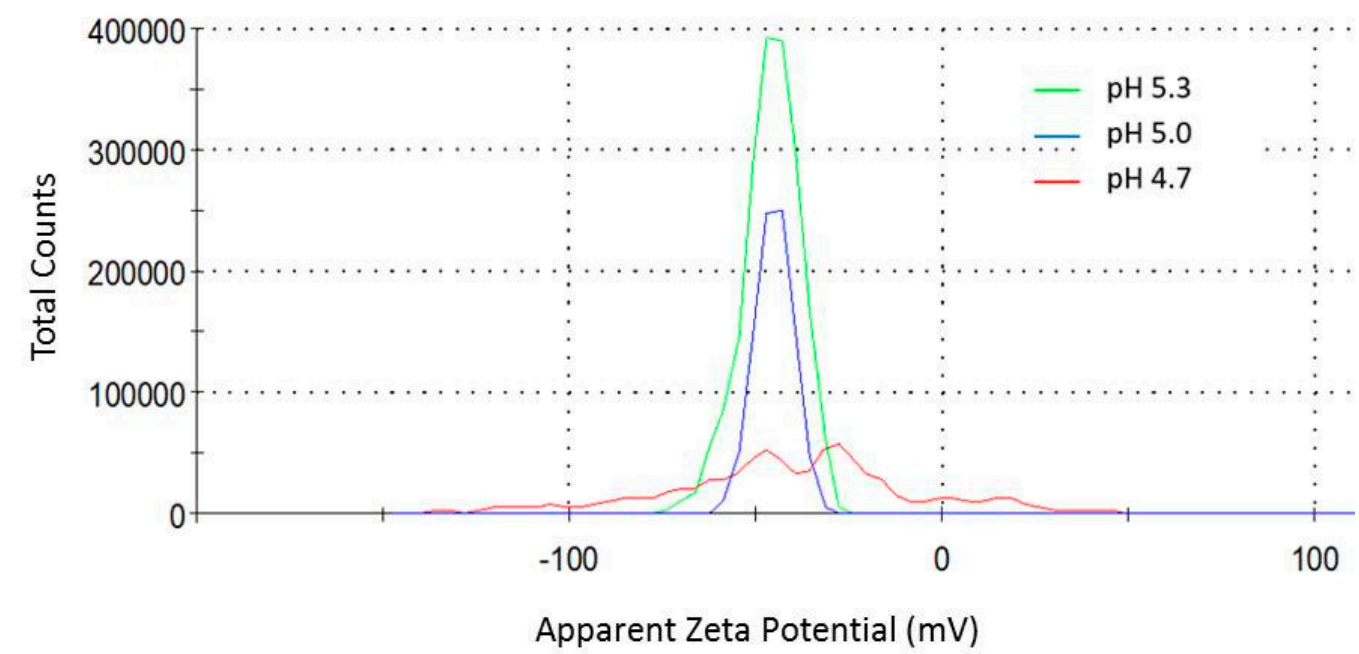

Figure 5. Zeta potential distribution $(\mathrm{mV})$ of citrate-capped AuNPs synthesized at $\mathrm{pH} 4.7$ (red), 5.0 (blue), and 5.3 (green).

The lowest dispersion values were determined at $\mathrm{pH} 5.0$ and $5.3(-44.9 \pm 5.1 \mathrm{mV}$ and $-45.7 \pm 7.6 \mathrm{mV}$, respectively), with curves showing single and narrow peaks. Similarly, a recent study showed that a $\mathrm{pH}$ value of 5 was optimal to produce gold nanoparticles that are highly monodisperse and spherical in shape, with a detrimental effect on the size polydispersity at lower $\mathrm{pH}$ values [30]. By contrast, the highest $\mathrm{pZ}$ dispersion was observed at $\mathrm{pH} 4.7(-42.2 \pm 35.1 \mathrm{mV})$, showing a flat distribution curve with three minor peaks that accounts for different populations of citrate-capped AuNPs having a wide range of surface charges. Importantly, the right tail of this curve mostly falls into the region of positive surface charge values (minor peak at $16.87 \pm 7.1 \mathrm{mV}$ ), revealing a loss on the citrate coverage of the gold surface. These results suggest that one can expect a lesser tendency of partially-protonated citrate ionic species to coordinate with the AuNPs at $\mathrm{pH}$ 4.7.

In order to understand the effect of $\mathrm{pH}$ on the synthesis reaction, the role of citrate (and protons) must be considered both in terms of the redox reaction forming AuNPs (citrate as oxidizer), as well as from the point of view of its protectant role (citrate as stabilizer). First, looking at the standard reaction mechanism, the initial step of this multiple-step process is the oxidation of citrate yielding dicarboxy acetone (Equation (1)). The second step consist of reduction of auric salt $\left(\mathrm{Au}^{3+}\right)$ to aurous salt $\left(\mathrm{Au}^{1+}\right)$ by accepting the electrons from the citrate oxidation reaction (Equation (2)), and the final step is the disproportionation of aurous species to gold atoms $\left(\mathrm{Au}^{0}\right)$ (Equation (3)):

$$
\begin{gathered}
\left({ }^{-} \mathrm{OCOCH}_{2}\right)_{2} \mathrm{C}(\mathrm{OH}) \mathrm{COO}^{-} \rightarrow\left({ }^{-} \mathrm{OCOCH}_{2}\right)_{2} \mathrm{C}=\mathrm{O}+\mathrm{CO}_{2}+\mathrm{H}^{+}+2 \mathrm{e}^{-} \\
\mathrm{AuCl}_{3}+2 \mathrm{e}^{-} \rightarrow \mathrm{AuCl}+2 \mathrm{Cl}^{-} \\
3 \mathrm{AuCl} \rightarrow 2 \mathrm{Au}+\mathrm{AuCl}_{3}
\end{gathered}
$$


The formation of an intermediate pentacoordinate complex of $\mathrm{Au}^{3+}$ species with dicarboxyacetone has been proposed, which subsequently decarboxylates to give $\mathrm{Au}^{+}$species [29]. However, the overall stoichiometry of the reduction reaction can be represented as:

$$
\begin{gathered}
2 \mathrm{AuCl}_{3}+3\left({ }^{-} \mathrm{OCOCH}_{2}\right)_{2} \mathrm{C}(\mathrm{OH}) \mathrm{COO}^{-} \rightarrow 2 \mathrm{Au}^{0}+3\left({ }^{-} \mathrm{OCOCH}_{2}\right)_{2} \mathrm{C} \\
=\mathrm{O}+6 \mathrm{Cl}^{-}+3 \mathrm{H}^{+}+3 \mathrm{CO}_{2} .
\end{gathered}
$$

In accordance with Le Chatelier's principle, as the concentration of protons increases in the solution, the tendency of citrate to oxidize decreases, as well as the availability of electrons to reduce the gold(III) chloride and to form AuNPs. In addition, coordination bonding between the gold surface and adsorbed molecules of citrate consist of carboxyl oxygens that contribute the electron pairs forming covalent bonds [29]. The complexity of the structural arrangement of the citrate layers on AuNPs has been analyzed in several recent studies, showing that citrate could coordinate to the gold through several different binding modes (geometries) that are mostly dictated by one or two of the terminus carboxyl groups [31-33]. However, to promote the intermolecular interactions it is required for citrate to diffuse on the gold surface in a preferential fully deprotonated form, since protonated carboxylate groups does not readily adsorb on gold due to electrochemical impediments [33]. Accordingly, the protonation of citrate terminus sites is considered to discourage citrate binding to the gold surface [32], in agreement with our observation of the detrimental effect of $\mathrm{pH}$ fluctuations on coverage, stabilization, and production of the AuNPs. However, future work is needed in order to gain a more detailed understanding of these specific sources of variability, by following a more comprehensive and statistically robust approach [34].

\section{Conclusions}

We have demonstrated that under standard experimental conditions of the citrate reduction method, gold nanoparticles are produced in variable concentrations, showing a $\mathrm{pH}$-dependent linear correlation in the range monitored between $\mathrm{pH} 4.7$ and 5.3 (typical $\mathrm{pH}$ fluctuation). The AuNP synthesis performance reduced by $46 \%$ from $2.4 \mathrm{nM}$ ( $\mathrm{pH} 5.3$ ) to $1.29 \mathrm{nM}$ (pH 4.7), without alteration of size and morphology. The physical characterization of the nanoparticles suggests that slight fluctuations of $\mathrm{pH}$ during synthesis can have an adverse effect on citrate oxidation, as well as on the availability of negative charges from carboxylate groups required for an optimal coverage, stabilization, and production of the nanoparticles. Overall, these results provide insight into the effect of the $\mathrm{pH}$ over the AuNP synthesis performance of the method, which would be of particular interest for further studies optimizing the reaction conditions in large-scale manufacturing processes.

Author Contributions: B.C.-T., V.D.-G., E.G.-G., and P.O. conceived and designed the experiments; B.C.-T. and V.D.-G. performed the experiments; B.C.-T., V.D.-G., E.G.-G., I.S., P.C., S.G., S.T., and P.O. analyzed the data; B.C.-T., V.D.-G., E.G.-G., and P.O. wrote the paper.

Funding: This study was supported by The Scientific and Technological Development Support Fund of Chile (FONDEF ID16I10221) and Dirección General de Investigación Universidad San Sebastián, Chile.

Acknowledgments: We thank Carlos von Plessing and José Villagra for valuable technical support.

Conflicts of Interest: The authors declare no conflict of interest.

\section{References}

1. Saha, K.; Agasti, S.S.; Kim, C.; Li, X.; Rotello, V.M. Gold nanoparticles in chemical and biological sensing. Chem. Rev. 2012, 112, 2739-2779. [CrossRef] [PubMed]

2. Radwan, S.H.; Azzazy, H.M. Gold nanoparticles for molecular diagnostics. Expert Rev. Mol. Diagn. 2009, 9, 511-524. [CrossRef] [PubMed]

3. Akhter, S.; Ahmad, M.Z.; Ahmad, F.J.; Storm, G.; Kok, R.J. Gold nanoparticles in theranostic oncology: Current state-of-the-art. Expert Opin. Drug Deliv. 2012, 9, 1225-1243. [CrossRef] [PubMed] 
4. Kim, D.; Oh, N.; Kim, K.; Lee, S.; Pack, C.G.; Park, J.H.; Park, Y. Label-free high-resolution 3-D imaging of gold nanoparticles inside live cells using optical diffraction tomography. Methods 2017, 136, 160-167. [CrossRef] [PubMed]

5. Zhang, J.; Liu, B.; Liu, H.; Zhang, X.; Tan, W. Aptamer-conjugated gold nanoparticles for bioanalysis. Nanomedicine 2013, 8, 983-993. [CrossRef] [PubMed]

6. Jacobs, M.; Panneer Selvam, A.; Craven, J.E.; Prasad, S. Antibody-conjugated gold nanoparticle-based immunosensor for ultra-sensitive detection of troponin-T. J. Lab. Autom. 2014, 19, 546-554. [CrossRef] [PubMed]

7. Amendola, V.; Pilot, R.; Frasconi, M.; Marago, O.M.; Iati, M.A. Surface plasmon resonance in gold nanoparticles: A review. J. Phys. Condens. Matter 2017, 29, 203002. [CrossRef] [PubMed]

8. Kelly, K.L.; Coronado, E.; Zhao, L.L.; Schatz, G.C. The optical properties of metal nanoparticles: The influence of size, shape, and dielectric environment. J. Phys. Chem. B 2003, 107, 668-677. [CrossRef]

9. Priyadarshini, E.; Pradhan, N. Metal-induced aggregation of valine capped gold nanoparticles: An efficient and rapid approach for colorimetric detection of $\mathrm{Pb}^{2+}$ ions. Sci. Rep. 2017, 7, 9278. [CrossRef] [PubMed]

10. Kim, Y.S.; Kim, J.H.; Kim, I.A.; Lee, S.J.; Jurng, J.; Gu, M.B. A novel colorimetric aptasensor using gold nanoparticle for a highly sensitive and specific detection of oxytetracycline. Biosens. Bioelectron. 2010, 26, 1644-1649. [CrossRef] [PubMed]

11. Luan, Y.; Chen, Z.; Xie, G.; Chen, J.; Lu, A.; Li, C.; Fu, H.; Ma, Z.; Wang, J. Rapid visual detection of aflatoxin B1 by label-free aptasensor using unmodified gold nanoparticles. J. Nanosci. Nanotechnol. 2015, 15, 1357-1361. [CrossRef] [PubMed]

12. Li, B.; Li, X.; Dong, Y.; Wang, B.; Li, D.; Shi, Y.; Wu, Y. Colorimetric sensor array based on gold nanoparticles with diverse surface charges for microorganisms identification. Anal. Chem. 2017, 89, 10639-10643. [CrossRef] [PubMed]

13. Zhao, P.; Li, N.; Astruc, D. State of the art in gold nanoparticle synthesis. Coord. Chem. Rev. 2013, 257, 638-665. [CrossRef]

14. Yang, S.; Wang, Y.; Wang, Q.; Zhang, R.; Ding, B. UV irradiation induced formation of Au nanoparticles at room temperature: The case of $\mathrm{pH}$ values. Colloids Surf. A Physicochem. Eng. Asp. 2007, 301, 174-183. [CrossRef]

15. Li, T.; Park, H.G.; Choi, S.H. $\gamma$-Irradiation-induced preparation of Ag and Au nanoparticles and their characterizations. Mater. Chem. Phys. 2007, 105, 325-330. [CrossRef]

16. Sadrolhosseini, A.R.; Abdul Rashid, S.; Zakaria, A. Synthesis of gold nanoparticles dispersed in palm oil using laser ablation technique. J. Nanomater. 2017, 2017, 6496390. [CrossRef]

17. Turkevich, J.; Stevenson, P.; Hillier, J. A study of the nucleation and growth process in the synthesis of colloidal gold. Discuss. Faraday Soc. 1951, 11, 55-75. [CrossRef]

18. Frens, G. Controlled nucleation for regulation of particle size in monodisperse gold suspensions. Nat. Phys. Sci. 1973, 241, 20-22. [CrossRef]

19. Sivaraman, S.K.; Kumar, S.; Santhanam, V. Monodisperse sub-10 nm gold nanoparticles by reversing the order of addition in Turkevich method-The role of chloroauric acid. J. Colloid Interface Sci. 2011, 361, 543-547. [CrossRef] [PubMed]

20. Husanua, E.; Chiappea, C.; Bernardinia, A.; Cappello, V.; Gemmi, M. Synthesis of colloidal Ag nanoparticles with citrate based ionic liquids as reducing and capping agents. Colloids Surf. A Physicochem. Eng. Asp. 2018, 538, 506-512. [CrossRef]

21. Kimling, J.; Maier, M.; Okenve, B.; Kotaidis, V.; Ballot, H.; Plech, A. Turkevich method for gold nanoparticle synthesis revisited. J. Phys. Chem. B 2006, 110, 15700-15707. [CrossRef] [PubMed]

22. Patungwasa, W.; Hodak, J. pH tunable morphology of the gold nanoparticles produced by citrate reduction. Mater. Chem. Phys. 2008, 108, 45-54. [CrossRef]

23. Ji, X.; Song, X.; Li, J.; Bai, Y.; Yang, W.; Peng, X. Size control of gold nanocrystals in citrate reduction: The third role of citrate. J. Am. Chem. Soc. 2007, 129, 13939-13948. [CrossRef] [PubMed]

24. Li, C.; Li, D.; Wan, G.; Xu, J.; Hou, W. Facile synthesis of concentrated gold nanoparticles with low size-distribution in water: Temperature and $\mathrm{pH}$ controls. Nanoscale Res. Lett. 2011, 6, 440. [CrossRef] [PubMed]

25. Manimegalai, S.; Sridharan, T.; Rameshpathy, M.; Devi Rajeswari, V. Recent trends and methodologies in gold nanoparticle synthesis-a prospective review on drug delivery aspect. OpenNano 2017, 2, 37-46. 
26. Weston, A.; Brown, P. HPLC and CE: Principles and Practice; Academic Press: San Diego, CA, USA, 1997.

27. Maye, M.; Han, L.; Kariuki, N.; Ly, N.; Chan, W.; Luo, J.; Zhong, C. Gold and alloy nanoparticles in solution and thin film assembly: Spectrophotometric determination of molar absorptivity. Anal. Chem. Acta 2003, 496, 17-27. [CrossRef]

28. Rasband, W. ImageJ. Available online: https://imagej.nih.gov/ij/ (accessed on 17 March 2018).

29. Al-Johani, H.; Abou-Hamad, E.; Jedidi, A.; Widdifield, C.M.; Viger-Gravel, J.; Sangaru, S.S.; Gajan, D.; Anjum, D.H.; Ould-Chikh, S.; Hedhili, M.N.; et al. The structure and binding mode of citrate in the stabilization of gold nanoparticles. Nat. Chem. 2017, 9, 890-895. [CrossRef] [PubMed]

30. Tyagi, H.; Kushwaha, A.; Kumar, A.; Aslam, M. A Facile pH controlled citrate-based reduction method for gold nanoparticle synthesis at room temperature. Nanoscale Res. Lett. 2016, 11, 362. [CrossRef] [PubMed]

31. Park, J.W.; Shumaker-Parry, J.S. Structural study of citrate layers on gold nanoparticles: Role of intermolecular interactions in stabilizing nanoparticles. J. Am. Chem. Soc. 2014, 136, 1907-1921. [CrossRef] [PubMed]

32. Monti, S.; Barcaro, G.; Sementa, L.; Carravetta, V.; Ågren, H. Characterization of the adsorption dynamics of trisodium citrate on gold in water solution. RSC Adv. 2017, 7, 49655-49663. [CrossRef]

33. Paik, W.; Han, S.; Shin, W.; Kim, Y. Adsorption of carboxylic acids on gold by anodic reaction. Langmuir 2003, 19, 4211-4216. [CrossRef]

34. Burrows, N.D.; Harvey, S.; Idesis, F.A.; Murphy, C.J. Understanding the seed-mediated growth of gold nanorods through a fractional factorial design of experiments. Langmuir 2016, 33, 1891-1907. [CrossRef] [PubMed]

(C) 2018 by the authors. Licensee MDPI, Basel, Switzerland. This article is an open access article distributed under the terms and conditions of the Creative Commons Attribution (CC BY) license (http://creativecommons.org/licenses/by/4.0/). 